\title{
Young Injectors: A Comparative Analysis of Risk Behaviour
}

\author{
S. Cassin, T. Geoghegan, G. Cox \\ The Merchants' Quay Project, Drugs/HIV Service, 4 Merchants' Quay, Dublin 8.
}

\begin{abstract}
This study compares the injecting and sexual risk-behaviour of young injectors, with injectors over the age of 25 . All respondents presented for the first time at the Merchants' Quay Health Promotion Unit between May 1st 1997 and February 28th 1998. Analysis revealed that the young injectors were significantly more likely to report recently borrowing and lending used injecting equipment, and injecting paraphernalia. Regarding sexual risk behaviour, younger respondents were proportionately more likely to report being sexually active, having multiple sexual partners, and having a regular partner who is an injecting drug user. However, they were significantly more likely than older clients to report condom use. The suggestion is that the harm minimisation message, which reached its zenith in the early 1990s, has now been somewhat de-emphasised in both policy and practice. Consequently, it is not reaching the young injectors who have recently initiated intravenous drug use. Additional strategies are needed to target this group of drug users, in order to promote positive behaviour changes.
\end{abstract}

\section{Introduction}

During the early 1980s Dublin experienced an unprecedented increase in illicit drug use and in particular intravenous heroin use ${ }^{1}$. This increase coupled with the growing international awareness of the risks of Human Immunodeficiency Virus (HIV) transmission through the shared use of infected injecting equipment, led to a shift in Irish drug policy. There was a move from the traditional abstinence orientated model of drug treatment to a more pragmatic harm reduction approach $^{2}$, which received official endorsement in the 1991 Government Strategy to Prevent Drug Misuse ${ }^{3}$. The reduction of drug-related harm, aims at achieving "intermediate goals" other than abstinence, such as safer drug use and avoiding health risks ${ }^{4}$, through a range of low threshold, outreach and crisis intervention services.

The Merchant's Quay Project established its Health Promotion Unit in 1992 to provide a model for working with drug injectors engaging in risky behaviour which concentrates on eliminating or reducing these risks. The name of the Unit reflects that it was not intended as a 'single' intervention, the exchange of new injecting equipment for used equipment. Rather, the Unit provides a range of services, all of which are considered to be an essential aspect of health promotion among injecting drug users (IDU's).

Some attempts have been made to measure the impact of various harm minimisation strategies on the levels of risk behaviour in drug injectors in Dublin. For example Williams et al $(1990)^{5}$ reported on the levels of risk behaviour among drug users enrolled in a methadone programme. Johnson et al (1994) $)^{6}$ measured the level of injecting and sexual risk behaviours of attendees at a Dublin syringe exchange. More recently Dorman et al (1997) ${ }^{7}$ illustrated that within their sample of in-treatment and out of treatment IDU's over half of the respondents reported sharing injecting equipment in the six months prior to interview, and 53 per cent reported never using condoms. 
The main objective of this paper is to provide some empirical data about younger injectors (i.e. under $25 \mathrm{yr}$ of age) levels of risk behaviour by comparing this client group with a cohort of older injectors. Young injectors are the focus of the study primarily because of the increase in the numbers of young Irish drug users presenting for treatment, which has been highlighted in the 1997 Annual Report of the European Monitoring Centre for Drugs and Drug Addiction ${ }^{8}$. According to this Report, Ireland is among a handful of countries consistently reporting increases in heroin use by new groups of young people. This was emphasised by the fact that the average age of drug users in treatment in Ireland was the lowest in Europe at $23.6 \mathrm{yr}$. Just over 65 per cent of individuals treated for drug problems in Ireland were under the age of 25, compared with only 43 per cent in the United Kingdom.

This paper expands on the findings of previous research on risk behaviour among drug injectors and presents baseline data on the injecting risk behaviour of young injectors compared with older injectors. This study has the advantage of not only having a large proportion of younger injectors ( 0.63$)$, thereby permitting the comparison, but also having a large proportion of recent injectors $(0.36)$ and female injectors $(0.25)$, sub-groups under-represented in many studies of IDU's.

\section{Method}

Information on all new clients at the Health Promotion Unit was collected by means of an Intervention Sheet at first attendance. This questionnaire is highly structured and gathers selfreported information on client's demographic characteristics and baseline information on clients' HIV risk behaviour, with respect to injecting drug use and sexual behaviour. Self-report of sexual behaviour $^{9}$ and drug use behaviour ${ }^{10}$ in IDU's has been demonstrated to be of acceptable reliability and validity. A similar questionnaire is repeated 3 months later in order to measure changes in clients to help assess the impact of Merchant's Quays Health Promotion Unit. The results of this follow-up will be reported at a later date.

A number of steps were taken in order to attempt to reduce non-response. The Intervention Sheet was piloted twice on a sample of clients and their comments on content and question wording were taken into consideration. This ensured that there was no ambiguity over the terminology used. All information on clients was collected by trained staff at the Merchant's Quay Project. Hence maximising the rapport between interviewer and client. The Intervention Sheets were completed in the Exchanges in the Health Promotion Unit, which have been designed to create a permissive non-threatening environment. The purpose of the Intervention Sheets in evaluating the Unit and its therapeutic benefits in helping workers to get a feel for the clients history and circumstances were explained to all new attenders. No pressure was placed on any clients to complete the Intervention Sheet, and it was made clear, that regardless they would receive the same quality of service. Clients were assured that the information provided would be kept confidential and would not jeopardise provision of treatment or other interventions offered by the Merchant's Quay Project.

The data set used here represents the total population of new clients attending the Health Promotion Unit ( $\mathrm{n}=770$ ) within the specified time frame, between May 1st 1997, and February 28th 1998. No client presenting within the time period refused to comply. Percentages are based on the above returns or valid responses adjusted for missing data. Missing data includes 
information not collected by staff at the project and non-response by clients. In order to examine the differences between Group I young injectors ( $<25 \mathrm{yr}$ of age) and Group II older injectors $(>25$ $\mathrm{yr}$ of age), for continuous variables such as, age of first drug use, age at first injecting and length of time injecting, T-tests were conducted. Chi-square analysis was conducted on categorical variables to test for differences between groups.

\section{Results}

\section{Drug Using Characteristics}

The major drug using characteristics of the sample are presented and compared in Table I (categorical variables) and Table II (continuous variables). Table I shows that younger injectors were significantly more likely to be female than clients over the age of 25 . There was no difference between the 2 groups in reported current contact with other drug treatment services. However, clients over the age of 25 were significantly more likely to report having undergone detoxification at some point in their drug taking career, which may indicate prior contact with drug treatment services.

As regards drug using history. Table II shows that clients under the age of 25 started using illicit drugs at a significantly younger age than clients over the age of 25 . The mean age of first drug use for the younger respondents was 16.99 , and for the older clients it was 22.57. Group I respondents were significantly more likely to report having

\section{TABLE I}

Drug Using Characteristics by Age (categorical variables)

\begin{tabular}{|c|c|c|c|c|}
\hline \multirow[t]{2}{*}{ Variables } & \multicolumn{4}{|c|}{ AGE STATUS } \\
\hline & $\begin{array}{c}\text { GROUP I } \\
<25 \text { years old } \\
(n=485)\end{array}$ & $\begin{array}{c}\text { GROUP II } \\
>25 \text { years old } \\
(n=285)\end{array}$ & $\begin{array}{c}\text { Chi- } \\
\text { Square }\end{array}$ & $p$ value \\
\hline Gender: male & $69.5 \%(337)$ & $84.6 \%(241)$ & 21.80 & $<0.000001$ \\
\hline female & $30.5 \%(148)$ & $15.4 \%(44)$ & & \\
\hline$\%$ in treatment & $18.6 \%(90)$ & $22.1 \%(63)$ & 1.35 & NS \\
\hline$\%$ had detox & $47.6 \%(231)$ & $59.6 \%(170)$ & 9.86 & $<0.01$ \\
\hline$\%$ Smoked prior to IV & $93.1 \%(442 / 475)$ & $75.8 \%(213 / 281)$ & 45.39 & $<0.000001$ \\
\hline$\%$ Using heroin* & $93.4 \%(453)$ & $88.1 \%(251)$ & 6.23 & $<0.05$ \\
\hline$\% \mathrm{IDU}^{*}$ & $91.1 \%(442)$ & $88.1 \%(251)$ & 1.47 & NS \\
\hline$\%$ Poly-drug use* & $67.4 \%(321 / 476)$ & $63.5 \%(179 / 282)$ & 1.23 & NS \\
\hline \% Daily IV use* & $82.1 \%(398)$ & $78.5 \%(219)$ & 2.65 & NS \\
\hline \% Living with IDU & $27.4 \%(132 / 482)$ & $29.5 \%(83 / 281)$ & 0.40 & NS \\
\hline
\end{tabular}

Total number of subjects are specified where there are missing data.

* Refers to the four weeks prior to contact with the Health Promotion Unit. 
TABLE II

Drug Using Characteristics by Age (Continuous variables)

\begin{tabular}{|c|c|c|c|c|}
\hline \multirow[t]{4}{*}{ Variables } & \multicolumn{4}{|c|}{ AGE STATUS } \\
\hline & GROUP I & GROUP II & & \\
\hline & $\begin{array}{c}<25 \text { years old } \\
(n=485)\end{array}$ & $\begin{array}{c}>25 \text { years old } \\
(n=285)\end{array}$ & & \\
\hline & Mean (SD) & Mean (SD) & T-Value & $p$ value \\
\hline Age first drug use & $16.99(2.5)$ & $22.57(5.7)$ & -15.00 & $<0.0005$ \\
\hline Time smoking* & $98.58(83.9)$ & $104.22(134.5)$ & -0.64 & NS \\
\hline Age first IV Time & $18.94(2.4)$ & $24.81(5.9)$ & -15.77 & $<0.0005$ \\
\hline $\mathrm{IV}^{*}$ & $65.71(87.71)$ & $269.08(333.64)$ & -10.03 & $<0.0005$ \\
\hline
\end{tabular}

* The mean times smoking and injecting are expressed in weeks.

smoked illicit drugs prior to their initiation into intravenous drug use. As illustrated in Table II there was no statistically significant differences between client groups in the length of time they reported smoking. However, respondents under the age of 25 initiated intravenous drug use at a significantly younger age than Group II respondents. As expected the older clients had significantly longer injecting careers, than did clients under the age of 25.

There was little reported difference in the current drug use of young injectors, and older injectors. Although, Table I illustrates that the young respondents were significantly more likely to report using heroin as their primary drug. There was no statistically significant difference between Group I and Group II clients in reported poly-drug use, and daily intravenous drug use over the four weeks prior to contact.

\section{Injecting and Sexual Risk-Taking Behaviour}

Table III presents and compares the injecting and sexual risk taking behaviour of Group I and Group II clients. Although the difference was not statistically significant, younger clients despite their shorter injecting histories were proportionately more likely to report having shared needles/syringes at some point in time. A further- distinction in the sharing of injecting equipment was made, that is in the recent borrowing and lending of used needle and syringes. Younger clients proved to be significantly more likely to report having both lent and borrowed used needles and syringes in the 4 weeks prior to first contact. Table III illustrates that of those clients with a sexual partner, the younger injectors were significantly more likely to report having a sexual partner who was also an IDU. Although the difference was not statistically significant, this client group was proportionately more likely to report sharing injecting equipment with their injecting sexual partner. The younger injectors in this cohort were also significantly more likely to report the recent sharing of injecting paraphernalia (i.e. spoons and filter); 64.3 per cent of Group I clients report such behaviour, compared with less than half of the clients over the age of 25. 
TABLE III

Injecting and Sexual Risk-taking Behaviour by Age Status

\begin{tabular}{|c|c|c|c|c|}
\hline \multirow[t]{2}{*}{ Variables } & \multicolumn{4}{|c|}{ AGE STATUS } \\
\hline & $\begin{array}{c}\text { GROUP I } \\
<25 \text { years old } \\
(n=485)\end{array}$ & $\begin{array}{c}\text { GROUP II } \\
>25 \text { years old } \\
(n=285)\end{array}$ & $\begin{array}{l}\text { Chi- } \\
\text { Square }\end{array}$ & $p$ value \\
\hline \multicolumn{5}{|l|}{$\%$ Ever shared } \\
\hline needles/syringes & $56.4 \%(268 / 475)$ & $53.0 \%(148 / 279)$ & 0.80 & NS \\
\hline$\%$ lent needles/syringes* & $18.1 \%(86 / 475)$ & $12.2 \%(34 / 278)$ & 2.9 & $<0.05$ \\
\hline \multicolumn{5}{|l|}{$\%$ borrowed needles/ } \\
\hline syringes* & $26.7 \%(127 / 475)$ & $17.3 \%(48 / 277)$ & 8.67 & $<0.01$ \\
\hline $\begin{array}{l}\% \text { shared } \\
\text { needles/syringes } \\
\text { with sexual partner* }\end{array}$ & $25.2 \%(78 / 310)$ & 19/1\%(41/189) & 2.48 & NS \\
\hline \multicolumn{5}{|l|}{$\%$ shared IV } \\
\hline paraphernalia* & $64.3 \%(305 / 474)$ & $43.8 \%(121 / 276)$ & 24.0 & $<0.000001$ \\
\hline$\%$ inject self & $73.3 \%(341 / 465)$ & $85.9 \%(237 / 276)$ & 15.86 & $<0.0001$ \\
\hline$\%$ sexually active ${ }^{a}$ & $77.1 \%(374)$ & $75.4 \%(215)$ & 0.28 & NS \\
\hline \multicolumn{5}{|l|}{$\%$ multiple sexual } \\
\hline partners $^{\mathrm{a}}$ & $28.5 \%(135 / 474)$ & $21.3 \%(60 / 282)$ & 4.79 & $<0.05$ \\
\hline$\%$ regular sexual partner & $66.3 \%(313 / 472)$ & $68.4 \%(193 / 282)$ & 0.36 & NS \\
\hline$\%$ IDU Partner ${ }^{1}$ & $41.9 \%(131 / 313)$ & $33.6 \%(65 / 193)$ & 3.66 & $<0.05$ \\
\hline$\%$ use condoms & $69.1 \%(328 / 475)$ & $58.2 \%(164 / 282)$ & 9.23 & $<0.000001$ \\
\hline$\% \mathrm{HIV}$ test & $38.4 \%(179 / 466)$ & $60.8 \%(166 / 273)$ & 34.68 & $<0.000001$ \\
\hline$\%$ vaccination Hep B & $10.9 \%(52 / 473)$ & $30.2 \%(84 / 278)$ & 44.25 & $<0.000001$ \\
\hline
\end{tabular}

*This refers to the four weeks prior to first contact

${ }^{\mathrm{a}}$ This refers to the three months prior to first contact

${ }^{1}$ This population relates to the clients who reported having a regular partner

Although the younger respondents were more likely to engage in injecting risk behaviour than older clients, as illustrated in Table III, they are significantly less likely to report having had a HIV test, or to have had a vaccination against Hepatitis B. Analysis also revealed that younger injectors were significantly less likely to be aware of their Hepatitis $B\left(X^{2}=23.58 ; d f=2\right.$; $\mathrm{p}<0.00001)$ and $\mathrm{C}$ status $\left(\mathrm{X}^{2}=24.75 ; \mathrm{df}=2 ; \mathrm{p}<0.0001\right)$, and whether they had jaundice $\left(\mathrm{X}^{2}=27.13\right.$; $\mathrm{df}=2 ; \mathrm{p}<0.0001)$, compared with clients over the age of 25 .

Regarding sexual risk behaviour. Table III illustrates that the majority of both Group I and Group 11 clients reported being sexually active in the 3 months prior to contact with the Health Promotion Unit. Younger clients were significantly more likely to report having had multiple sexual partners in that time period. In their favour, respondents under the age of 25 were significantly more likely to report using condoms. 


\section{Discussion}

The importance of this study is in the information afforded by the comparison of the group of under $25 \mathrm{yr}$ old $(\mathrm{n}=485)$ and over $25 \mathrm{yr}$ old $(\mathrm{n}=285)$ first time presenters at the Merchant's Quay Health Promotion Unit. The research findings present serious cause for concern as they depict high levels of risk behaviour both in terms of injecting and in terms of sexual practices. Despite the increase in the number of drug treatment programmes and the extensive public HIV prevention campaigns there has not been a diminution in the risk behaviour amongst this client group. Areas of particular concern include the very young age that respondents under 25 reported initiating intravenous drug use (mean 18.94), the presence of a large proportion of young female injectors (0.25), and the lack of awareness among the younger respondents of their HIV and Hepatitis B or C status given their level of risk behaviours.

International research has identified factors other than youth itself ${ }^{11}$, which are associated with high levels of injecting and sexual, risk behaviour. Included among these are poly-drug use $^{12}$, having a sexual partner who is an IDU ${ }^{13}$, having multiple sexual partners, and living with an $\mathrm{IDU}^{14}$. This research illustrated that significant proportions of young injectors fall into the aforementioned categories.

The research findings also confirm the high levels of risk behaviour among IDU's recorded by previous Irish studies ${ }^{5,6,7}$, but in comparing the younger and older cohorts it highlights the higher level of risk behaviour among the younger groups. One might expect that the less experienced drug user by virtue of their age, shorter drug taking histories, and lack of engagement with services, might be prone to more risk taking behaviour. However, this raises another set of questions about the effectiveness of prevention and awareness programmes in targeting young drug users or potential young drug users.

The study indicates that the younger respondents were slightly more likely to report having shared needles and syringes than the older clients; 56.4 per cent of the younger group shared as against 53 per cent of the older group. This level of sharing is consistent with a 1997 study by Dorman et al, which recorded 55.7 per cent as having reported sharing equipment ${ }^{7}$. A more detailed examination of sharing behaviour illustrates that 26.7 per cent of the younger injectors reported the recent borrowing of used injecting equipment. The lending and borrowing of needles/syringes differ markedly in terms of levels of personal risk and risk of HIV and Hepatitis transmission $^{15}$, in that injectors who use others' injecting equipment potentially risk becoming infected (or re-infected) with HIV or Hepatitis. This high level of borrowing has serious public health implications.

Previous studies have shown that drug users are highly sexually active ${ }^{16}$ and that condom use among this group is relatively low ${ }^{17}$. Our research findings reveal that both age groups reported being sexually active, 77.1 per cent of the younger group and 75.4 per cent of the older group, with 28.5 per cent of the younger group and 21.3 per cent of the older group having multiple partners. However, the younger group reported significantly higher condom use than the older group, 69.1 per cent as against 58.2 per cent. International research corroborates the position that sexual behaviour is more difficult to change than needle sharing behaviour ${ }^{18}$. However this study raises challenging questions in this regard. It could be argued that information campaigns regarding safer sex have had a more significant impact on the younger age group than 
those campaigns pertaining to safer drug use practices. This is especially evident in the comparisons of sharing injecting paraphernalia. Forty six per cent of the older group reported the sharing of injecting paraphernalia (i.e. spoons and filters) as opposed to 64.3 per cent of the younger group. As the transmission of Hepatitis $\mathrm{C}$ and HIV has been linked to these sharing practices $^{14}$ the implications are obviously very serious. The younger group were also significantly less likely to have tested for HIV, 38.4 per cent as against 60.8 per cent of the older group and significantly less likely to have been vaccinated against hepatitis B, 10.9 per cent against 30.2 per cent of the older group.

In conclusion our research findings reveal alarming risk taking behaviours among younger drug users. These behaviours relate to sexual activity and the sharing of injecting equipment and have serious implications for the transmission of HIV and Hepatitis among the drug using population, and potentially into the wider population. There are subsequent implications for the drug treatment facilities, health services, the police and the criminal justice system over the coming years. These systems have not yet had to cope with a large number of young drug users, a significant proportion of whom will be women.

Our findings appear to indicate that previous and contemporary drug prevention and awareness raising campaigns have not succeeded in impacting sufficiently to change the risk behaviour of young drug users. There are clear messages emerging from this research with regard to policy formulation and service provision. In the first instance young drug users need to be identified at an early stage in their using cycle and their information needs to be established and addressed. The emphasis on harm reduction should be reiterated for current young drug users and a range of accessible locally delivered and coordinated services should be established. This will ensure that young drug users are aware of the consequences of their risk behaviours and may choose to engage in safer practices to minimise that risk. On a wider scale, any significant consequences will hopefully result in a decrease in the transmission of HIV and Hepatitis C representing a very positive step forward.

\section{Acknowledgements}

We would like to thank all clients and staff at Merchants' Quay Project for collaborating with the research. In particular the Supervisor of the Health Promotion Unit, Irene Farrelly. The research on which this paper draws was partially funded by the Dublin Inner City Trust.

\section{References}

1. Dean, G., Kelly, M., O'Hare, A., Kelly, G., O'Connor, A. The Opiate Epidemic in Dublin 1979-1983. Irish Medical Journal 1985; 78:4: 107-10.

2. Butler, S. Drug Problems and Drug Policies in Ireland: A Quarter of a Century Review. Administration 1991; 39: 210-33.

3. Department of Health. Government Strategy to Prevent Drug Misuse. Dublin 1991.

4. O'Hare, P., Newcombe, R, Matthews, A., Burning, E., Drucker, E. The Reduction of DrugRelated Harm. London: Routledge, 1992.

5. Williams, H., Mullan, E., O'Connor, J., Kinsella, A. Risk behaviour for HIV transmission in attenders on methadone maintenance. Irish J. of Med. Sci. 1990. May: 141-44.

6. Johnson, Z., O'Connor, M., Pomeroy, L. et al. Prevalence of HIV and associated risk behaviour in attendees at a Dublin needle exchange. Addiction 1994; 89: 603-7.

7. Dorman, A., Keenan, E., Schuttler, C., Merry, J., O’Connor, J. HIV risk behaviour in Irish intravenous drug users. Irish J. Med. Sci. 1997; 166:4: 235-38. 
8. EMCDDA. Annual Report on the State of the Drugs Problem in the European Union. Luxembourg; 1997

9. Kleun, J., Schwebke, J., Holmes, K. The validity of injecting drug users self-report about sexually transmitted disease: A Comparison of survey and serological data. Addiction 1994; 88: 673-80.

10. McElrath, K., Chitwood, D., Griffin, D., Comerford, M. The consistency of self-reported HIV risk behaviour among injecting drug users. American Journal of Public Health 1994; 84:12: 1965-70.

11. Donoghoe, M., Dolan, K., Stimson, G. Life-style factors and social circumstances of syringe sharing in injecting drug users. British Journal of Addiction 1992; 87: 993-1003.

12. Klee, H., Faugier, H., Hayes, C., Boulton, T, Morris, J. AIDS related risk behaviour, polydrug use and temazepam. British Journal of Addiction 1990; 85: 1125-32.

13. Magura, S., Grossman, J., Lipton, D. et al. Determinants of needle sharing among intravenous drug users. American Journal of Public Health 1989; 79:4: 459-62.

14. Samuels, J., Vlahov, D., Anthony, J., Chaisson, R. Measurement of HIV risk behaviours among intravenous drug users. British Journal of Addiction 1992; 87: 417-28.

15. McKeganey, N., Bloor, P., Watson, H. Risks of sharing injecting equipment. British Med, Jour. 1988; 297: 1474.

16. Stimson, G., Lart, R., Dolan, K., Donoghoe, M. The future of syringe exchanges in the public health prevention of HIV Infection. (Ed.) Aggleton, P., Hart, G., Davies, P. AIDS: Responses, Interventions and Care. The Falmer Press. London.

17. Keene, J., Stimson, G., Jones, S., Parry-Langon, N. Evaluation of syringe-exchange for HIV prevention among injecting drug users in rural and urban areas of Wales. Addiction 1993; 88: 1063-70.

18. Dongohoe, M., Stimson, G, Dolan, K. Sexual behaviour of injecting drug users and associated risks of HIV infection for non-injecting sexual partners. AIDS Care 1989; 1:5158. 